\title{
Análise quantitativa de risco: Paiol de explosivos utilizados no processo de canhoneio de um poço de petróleo
}

\author{
Quantitative Risk Analysis: Storeroom of explosives used in the process of cannonading of an oil well
}

\section{Leonardo Vinícius Lopes de Mendonça'; Carlos Enrique de Medeiros Jerônimo²}

' Engenhero Mecânico, Universidade Potiguar, Natal, Brasil

${ }^{2}$ Doutor em Engenharia Química. Professor da Universidade Potiguar e Universidade Federal do Rio Grande do Norte, Natal, Brasil

\begin{abstract}
Resumo
O presente estudo busca realizar uma análise quantitativa dos riscos presentes no armazenamento de cargas explosivas utilizadas no processo de canhoneio, técnica usada no processo de completação de poços de petróleo, que visa a comunicação limpa e efetiva entre o poço e a formação. Esse processo se refere à perfuração do revestimento, do cimento e da formação através de cargas explosivas. Por meio de cenários distintos, pode-se quantificar por meio do método probit os riscos oriundos nos paióis de cargas explosivas e radioativas utilizadas no serviço de canhoneio, com o dimensionamento das áreas de vulnerabilidade e riscos associados às atividades desenvolvidas. Os dados foram coletados e utilizados para a quantificação dos riscos de cada cenário, onde por meio dos resultados pode-se interpretar e mostrar o quanto o raio de trabalho em relação aos paióis são atingidos caso algum sinistro ocorra. Os resultados obtidos com o trabalho demonstraram os impactos que um acidente envolvendo cargas explosivas causaria no local e em sua vizinhança. Com o conhecimento do volume total de explosivos presentes no paiol, pode-se quantificar a distância mínima atingida devido aos cenários estudados.
\end{abstract}

Palavras-chave: Canhoneio. Cargas explosivas. Segurança no trabalho. Probit. Análise quantitativa de riscos.

\begin{abstract}
The present study aims to conduct a quantitative analysis of the risks present in the storage of explosive charges used in the cannonade process technique used in oil well completion process, which aims to clear and effective communication between the well and the formation. This case refers to the perforation of the coating, cement and training by explosive charges. By means of different scenarios can be quantified by means of probit risks arising in storerooms and radioactive explosive charges used in the cannonade service, sizing the areas of vulnerability and risks associated with the activity method. Data were collected and used to quantify the risks of each scenario, where by the results can be interpreted and show how working radius relative to the bunkers are achieved if some event occurs. The results obtained from the study showed the impact that an accident involving explosive charges would cause onsite and in your neighborhood. With knowledge of the total amount of explosive present in the magazine, one can quantify the minimum distance achieved due to the scenarios studied.
\end{abstract}

Keywords: Cannonade.Explosive charges. Safety at work. Probit. Quantitative Risk Analysis 


\section{INTRODUÇÃO}

Atualmente a indústria petrolífera está no centro do sistema produtivo, pois o petróleo é a principal fonte de energia não só do Brasil, mas do mundo, que move a produção material estando presente em vários e poderosos setores industriais. Hoje o Brasil ocupa uma posição importante no mercado de petróleo, onde a produção saiu do patamar de 1 milhão de barris/dia para 2,5 milhões de barris/dia em pouco mais de uma década e a tendência que esse valor aumente, principalmente que o surgimento e exploração do pré-sal (ANP, 2013).

A produção de petróleo passa por diversas fases, desde a prospecção das áreas possíveis de sua ocorrência (bacias sedimentares nas quais, em milhões de anos, foram soterrados e decompostos restos de florestas), depois a avaliação econômica da jazida e a efetiva extração do petróleo e seu refino. Ao terminar a perfuração de um poço, é necessário deixá-lo em condições de operar, de forma segura e econômica, durante toda sua vida produtiva. Ao conjunto de operações destinadas a equipar o poço para produzir óleo e gás (ou ainda injetar fluidos nos reservatórios) denomina-se completação (Thomas, 2001).

O requisito mínimo para que possa haver algum sucesso na completação de um poço é o estabelecimento de uma comunicação limpa e efetiva entre o poço e a formação. Dentre as técnicas para a perfuração desse canal de comunicação poço / formação, a mais comumente utilizada é conhecida como canhoneio. Ela se refere à perfuração do revestimento, do cimento e da formação através de cargas explosivas. Este canhoneio é feito para comunicar o interior do poço com a zona de interesse. Se o poço é revestido e não-perfurado durante os estágios iniciais da operação de perfuração, o controle do poço é mais fácil e os custos de completação podem ser reduzidos (Thomas, 2001).

Há empresas que mantém confinado uma considerável quantidade de explosivos, onde podemos citar os paióis de explosivos para canhoneio de poços de petróleo. Segundo as Normas Reguladoras de Mineração (NRM), mais precisamente a NRM 16.3, o armazenamento dos mesmos deve seguir os seguintes pré-requisitos:

16.3.1 A localização, construção e manutenção dos paióis e armazenagem de explosivos e acessórios devem estar de acordo com a regulamentação vigente do Ministério da Defesa.

16.3.2 Os paióis de explosivos ou acessórios no subsolo não devem estar localizados junto a galerias de acesso de pessoal e de ventilação principal da mina.

16.3.3 Nos acessos aos paióis de explosivos ou acessórios devem estar disponíveis dispositivos de combate a incêndios.

16.3.4 O acesso aos paióis de explosivos ou acessórios só deve ser liberado a pessoal devidamente qualificado, treinado e autorizado ou acompanhado de pessoa que atenda a estas qualificações.

16.3.5 Os locais de armazenamento de explosivos ou acessórios no subsolo devem:

a) conter no máximo a quantidade a ser utilizada num período de 5 (cinco) dias de trabalho;

b)ser protegidos deimpactos acidentais;

c) ser trancados sob guarda de técnico responsável ou bláster;

d)ser independentes, separados e sinalizados;

e) ser sinalizados na planta da mina indicando-se sua capacidade e

f) ser livres de umidade excessiva e onde a ventilação possibilite manter a temperatura

adequada e minimizar o arraste de gases para as frentes de trabalho em caso de acidente.

16.3.6 Em todos os paióis de explosivos ou acessórios devem ser anotados os estoques semanais e movimentações de materiais, sendo que os registros devem ser examinados e conferidos periodicamente pelo bláster e pelo responsável pela mina.

16.3.6.1 Os registros de estocagem e movimentações de materiais devem estar disponíveis para a fiscalização. 
16.3.7 É proibida a estocagem de explosivos e acessórios fora de locais apropriados.

16.3.8 Os explosivos e acessórios não usados devem retornar imediatamente aos respectivos locais de armazenamento.

16.3.9 A menos de $20 \mathrm{~m}$ (vinte metros) de armazenamento de explosivos ou acessórios só é permitido o acesso de pessoas que trabalhem naquela área para execução de manutenção das galerias e de trabalhos nos paióis.

16.3.10 No subsolo, dentro de paióis de explosivos ou acessórios e a menos de $25 \mathrm{~m}$ (vinte cinco metros) dos mesmos o sistema de contenção deve ser constituído, preferencialmente, de material incombustível e não podendo existir disposição de qualquer outro material.

16.3.11 Os explosivos e acessórios devem ser estocados em suas embalagens originais ou em recipientes apropriados e sobre material não metálico, resistente e livre de umidade.

16.3.12 Os paióis de explosivos ou acessórios devem ser sinalizados com placas de advertência contendo a menção "EXPLOSIVOS", em locais visíveis nas proximidades e nas portas de acesso aos mesmos, sem prejuízo das demais sinalizações previstas em normas vigentes.

Além dessas medidas de proteção, é de suma importância a aplicação do processo de Análise Quantitativa de Riscos, pois o mesmo tem o objetivo de averiguar numericamente a probabilidade de cada risco e de sua respectiva consequência nos objetivos do projeto, assim como a extensão do risco geral do projeto. Análise quantitativa de risco geralmente segue a análise qualitativa de risco, no qual ela requer a identificação de risco. Os processos de análise quantitativa e qualitativa de risco podem ser usados separadamente ou juntos. Nesse trabalho é realizado um estudo por meio de simulações matemáticas dos riscos associados a um empreendimento de prestação de serviços de canhoneio de poços de petróleo, objetivando a parametrização das distâncias seguras e zonas de impacto da referida atividade.

\section{METODOLOGIA}

\section{I DEFINIÇÃO DE RISCO}

A Nota Técnica de Prevenção NTP 330 redigida por Belloví (2004), propulsora do método simplificado de avaliação de risco, conceitua risco como "uma combinação da probabilidade e da conseqüência da ocorrência de um determinado acontecimento perigoso". O risco é definido como o produto da probabilidade de uma ocorrência pela sua severidade, entendida como a conseqüência provocada pela ocorrência.

A Equação 1 abaixo evidencia a relação entre perigo e risco de um determinado evento perigoso:

$$
\mathrm{R}=\mathrm{P} \times \mathrm{C}
$$

Onde R é o risco, $\mathrm{P}$ a probabilidade da ocorrência, e $\mathrm{C}$ são as conseqüências.

\subsection{ANÁLISE PRELIMINAR DE RISCO}

Neste trabalho foi desenvolvida uma Análise Preliminar de Risco (APR), também denominada Preliminary Hazard Analysis (PHA) é uma técnica de avaliação qualitativa desenvolvida e aplicada inicialmente na área militar para a revisão de novos sistemas de mísseis.A APR é realizada durante a fase inicial de desenvolvimento de um projeto ou sistema, com a finalidade de determinar os riscos que poderão estar presentes na fase operacional. Por meio desta técnica, as mudanças necessárias decorrentes dos riscos identificados podem ser realizadas na fase de projeto do processo, de maneira mais fácil, resultando em uma economia de custos do empreendimento. Para a seleção das técnicas 
aplicáveis, e conseqüentemente definição da APR, tomou-se como base as orientações da CETESB (2003) e elenco de aspectos, impactos, perigos e situações de emergências (AIPRES) analisadas.

Para este estudo, em questão, foram analisadas as seguintes tarefas:

\begin{tabular}{|c|c|c|}
\hline Evento & Motivo & Conseqüência \\
\hline $\begin{array}{c}\text { Acúmulo de eletricidade } \\
\text { estática no paiol }\end{array}$ & $\begin{array}{c}\text { Baixa umidade relativa } \\
\text { do ar ou falha no } \\
\text { sistema de aterramento } \\
\text { de explosivos }\end{array}$ & $\begin{array}{c}\text { Danos leves aos } \\
\text { equipamentos, sem } \\
\text { lesões à tripulação }\end{array}$ \\
\hline $\begin{array}{c}\text { Alta temperatura no } \\
\text { interior do paiol }\end{array}$ & $\begin{array}{c}\text { Falha no resfriamento do } \\
\text { paiol }\end{array}$ & $\begin{array}{c}\text { Danos aos } \\
\text { equipamentos, porém } \\
\text { sem lesão à tripulação }\end{array}$ \\
\hline $\begin{array}{c}\text { Centelhamento no } \\
\text { interior do paiol }\end{array}$ & $\begin{array}{c}\text { Falha no sistema de } \\
\text { descarga atmosférica }\end{array}$ & $\begin{array}{c}\text { Danos irreparáveis com } \\
\text { mortes ou lesões graves }\end{array}$ \\
\hline $\begin{array}{c}\text { Iniciação devido a outro } \\
\text { paiol próximo }\end{array}$ & $\begin{array}{c}\text { Explosão de um paiol } \\
\text { próximo }\end{array}$ & $\begin{array}{c}\text { Danos irreparáveis com } \\
\text { mortes ou lesões graves }\end{array}$ \\
\hline
\end{tabular}

Fonte: Autores.

Para priorização das recomendações geradas foi utilizada a matriz de tolerabilidade de riscos, conforme abaixo:

FREQUÊNCIA:

\begin{tabular}{|c|c|c|c|c|c|c|c|}
\hline \multicolumn{6}{|c|}{ Frequência } & \multirow{6}{*}{ 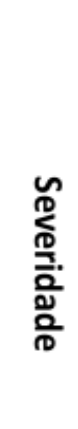 } & \multirow{2}{*}{$\begin{array}{c}\text { Legenda } \\
\text { Risco }\end{array}$} \\
\hline A & B & C & D & $E$ & & & \\
\hline$\overline{2}$ & 3 & 4 & 5 & 5 & IV & & 1 - Desprezível \\
\hline 1 & 2 & 3 & 4 & 5 & III & & 3-Moderado \\
\hline 1 & 1 & 2 & 3 & 4 & II & & 4 - Sério \\
\hline 1 & 1 & 1 & 2 & 3 & I & & \\
\hline
\end{tabular}


SEVERIDADE:

\begin{tabular}{|c||c||l||}
\hline Cat. & Denominação & \multicolumn{1}{c||}{ Descrição } \\
\hline \hline 1 & Desprezível & $\begin{array}{l}\text { Sem danos ou danos insignificantes aos equipamentos, à } \\
\text { propriedade e/ou meio ambiente } \\
\text { Não ocorrem lesões/mortes de funcionários, de terceiros (não } \\
\text { funcionários) e/ou de pessoas extra-muros- (indústrias e } \\
\text { comunidade); o máximo que pode ocorrer são casos de primeiros } \\
\text { socorros ou tratamento médico menor }\end{array}$ \\
\hline \hline 2 & Marginal & $\begin{array}{l}\text { Danos leves aos equipamentos, à propriedade e/ou ao meio } \\
\text { ambiente (danos materiais são controláveis e/ou de baixo custo de } \\
\text { reparo); } \\
\text { Lesões leves em funcionáriqsterceiros e/ou em pessoas extra } \\
\text { muros. }\end{array}$ \\
\hline \hline 3 & Crítica & $\begin{array}{l}\text { Danos severos aos equipamentos, à propriedade e/ou ao meio } \\
\text { ambiente, levando à para ordenada da unidade e/ou sistema } \\
\text { Lesões de gravidade moderada em funcionários, em terceiros e/ou } \\
\text { em pessoas extra -muros (probabilidade remota de morte de } \\
\text { funcionários e/ou terceiros); } \\
\text { Exige ações corretivas imediatas para evitar se desdobramento em } \\
\text { catástrofe. }\end{array}$ \\
\hline \hline 4 & Catastrófical & $\begin{array}{l}\text { Danos irreparáveis aos equipamentos, à propriedade e/ou ao meio } \\
\text { ambiente, levando à parada desor denada da unidade e/ou sistema } \\
\text { (reparação lenta ou impossível); } \\
\text { Provoca mortes ou lesões graves em várias pessoas (em } \\
\text { funcionários, em terceiros e/ou em pessoas extra-muros) }\end{array}$ \\
\hline \hline
\end{tabular}

Fonte: CETESB (2003)

\section{CLASSIFICAÇÃO DO RISCO:}

\begin{tabular}{|c|c|c|c|c|c|}
\hline & & \multicolumn{4}{|c|}{ Severidade } \\
\hline & & 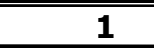 & 2 & 3 & 4 \\
\hline \multirow{4}{*}{ Freqüência } & 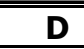 & RNC & RM & RC & RC \\
\hline & $\mathbf{C}$ & RNC & RM & RM & $\mathbf{R C}$ \\
\hline & B & RNC & RNC & RM & RM \\
\hline & $\mathbf{A}$ & RNC & RNC & RNC & RM \\
\hline \multicolumn{2}{|c|}{$\begin{array}{l}\text { Freqüência: } \\
\text { A=Remota } \\
\text { B=Pouco provável } \\
C=\text { Provável } \\
D=\text { Frequente }\end{array}$} & $\begin{array}{l}1=\text { Desprez } \\
2=\text { Margina } \\
3=\text { Crítica } \\
4=\text { Catastró }\end{array}$ & & \multicolumn{2}{|c|}{$\begin{array}{l}\text { Risco: } \\
\text { RC=Risco Crítico } \\
\text { RM=Risco Moderado } \\
\text { RNC= Risco Não-Crítico }\end{array}$} \\
\hline
\end{tabular}

Fonte: CETESB (2003)

Alguns sinônimos podem ser utilizados, a saber: toleráveis (não-crítico) e não toleráveis (crítico).

\subsection{ANÁLISE DE VULNERABILIDADE}

As equações de Probit, que permitem relacionar a intensidade do efeito físico com o nível de danos esperado, são da seguinte forma:

$$
\text { Onde: } \quad \mathrm{Y}=\mathrm{k} 1+\mathrm{K} 2 \ln (\mathrm{V})
$$

$Y=$ Probit a que está relacionada a percentagem de recurso vulnerável (pessoas, estruturas, etc.) que é afetada pelo acidente;

$\mathrm{V}=$ medida da intensidade do efeito físico causador dos danos aos recursos vulneráveis (sobrepressão, impulso, intensidade de fluxo térmico e tempo de exposição ou concentração e tempo de exposição); 
k1 e k2 = parâmetros específicos para cada tipo de dano e de substância.

Segue abaixo a tabela de correlação entre o tipo de ferimento ou dano com a variável casual "V" e os parâmetros Probit "k1" e "k2":

\begin{tabular}{|c|c|c|c|}
\hline \multirow[t]{2}{*}{ Tipo de Ferimento ou Dano } & \multirow{2}{*}{$\begin{array}{c}\text { Variável } \\
\text { Causal"V" }\end{array}$} & \multicolumn{2}{|c|}{ Parâmetro Probit } \\
\hline & & $\mathbf{k}_{1}$ & $\mathbf{k}_{2}$ \\
\hline $\begin{array}{l}\text { INCÊNDIOS: }\left(\mathrm{W} / \mathrm{M}^{2}\right) \\
\text { - Mortes por queimadura devido a incêndio } \\
\text { em poça, jato ou bola de fogo (Eisenberg) } \\
\text { - Queimadura não-letal de } 1^{\circ} \mathrm{grau}\end{array}$ & $\begin{array}{l}\mathrm{t} \mathrm{I}^{4 / 3} / 10^{4} \\
\mathrm{t} \mathrm{I}^{4 / 3} / 10^{4}\end{array}$ & $\begin{array}{l}-14,9 \\
-39,83\end{array}$ & $\begin{array}{l}2,56 \\
3,0186\end{array}$ \\
\hline - Queimadura não-letal de $2^{\circ}$ grau & $\mathrm{t} \mathrm{I}^{4 / 3} / 10^{4}$ & $-43,14$ & 3,0186 \\
\hline $\begin{array}{l}\text { EXPLOSÕES: } \\
\text { Morte por hemorragia pulmonar } \\
\text { Ruptura de tímpanos } \\
\text { Morte por impacto } \\
\text { Ferimentos por impacto } \\
\text { Ferimentos por objetos voadores } \\
\text { Danos estruturais } \\
\text { Vidros quebrados }\end{array}$ & $\begin{array}{l}\mathrm{p}^{\circ} \\
\mathrm{p}^{\circ} \\
\mathrm{J} \\
\mathrm{J} \\
\mathrm{J} \\
\mathrm{p}^{\circ} \\
\mathrm{p}^{\circ}\end{array}$ & $\begin{array}{l}-77,1 \\
-15,6 \\
-46,1 \\
-39,1 \\
-27,1 \\
-23,8 \\
-18,1\end{array}$ & $\begin{array}{l}6,91 \\
1,93 \\
4,82 \\
4,45 \\
4,26 \\
2,92 \\
2,79\end{array}$ \\
\hline $\begin{array}{l}\text { LIBERAÇõES TóxICAS } \\
\text { Mortes por exposição a cloro } \\
\text { Ferimentos por exposição a cloro } \\
\text { Mortes por exposição à amônia }\end{array}$ & $\begin{array}{l}\Sigma \mathrm{C}^{2,75} \mathrm{~T} \\
\quad \mathrm{C} \\
\Sigma \mathrm{C}^{2,75} \mathrm{~T}\end{array}$ & $\begin{array}{l}-17,1 \\
-2,40 \\
-30,57\end{array}$ & $\begin{array}{l}1,69 \\
2,90 \\
1,385\end{array}$ \\
\hline
\end{tabular}

Fonte: TNO (2005)

A variável Y, denominada Probit (Probability Unit), é uma variável aleatória distribuída, normalmente com valor médio igual a 5 . A percentagem do recurso vulnerável afetado corresponde à função de distribuição acumulada de Y, sendo esta relação definida pela equação:

$$
P=\frac{1}{2 \pi} \int_{-\infty}^{y=5} \exp -\left(u^{2} / 2\right) d u
$$

Esta correspondência matemática é mais fácil de ser utilizada na forma de uma tabela, conforme mostrado a seguir, na qual a primeira linha e a primeira coluna indicam a percentagem do recurso vulnerável afetado correspondente aos valores de Probit constantes das demais linhas e colunas.

Tabela 1. Matriz de percentual de fatalidade versus valor do Probit.

\begin{tabular}{|c|c|c|c|c|c|c|c|c|c|c|}
\hline$\%$ & 0 & 1 & 2 & 3 & 4 & 5 & 6 & 7 & 8 & 9 \\
\hline 0 & -- & 2.67 & 2.95 & 3.12 & 3.25 & 3.36 & 3.45 & 3.52 & 3.59 & 3.66 \\
\hline 10 & 3.72 & 3.77 & 3.82 & 3.87 & 3.92 & 3.96 & 4.01 & 4.05 & 4.08 & 4.12 \\
\hline 20 & 4.16 & 4.19 & 4.23 & 4.26 & 4.29 & 4.33 & 4.36 & 4.39 & 4.42 & 4.45 \\
\hline 30 & 4.48 & 4.50 & 4.53 & 4.56 & 4.59 & 4.61 & 4.64 & 4.67 & 4.69 & 4.72 \\
\hline 40 & $4.7 \mathrm{~s}$ & 4.77 & 4.80 & 4.82 & 4.85 & 4.87 & 4.90 & 4.92 & 4.95 & 4.97 \\
\hline 50 & 5.00 & 5.03 & 5.05 & 5.08 & 5.10 & 5.13 & 5.15 & 5.18 & 5.20 & 5.23 \\
\hline 60 & 5.25 & 5.28 & 5.31 & 5.33 & 5.36 & 5.39 & 5.41 & 5.44 & 5.47 & 5.50 \\
\hline 70 & 5.52 & 5.55 & 5.58 & 5.61 & 5.64 & 5.67 & 5.71 & 5.74 & 5.77 & 5.81 \\
\hline 80 & 5.84 & 5.88 & 5.92 & 5.95 & 5.99 & 6.04 & 6.08 & 6.13 & 6.18 & 6.23 \\
\hline \multirow[t]{2}{*}{90} & 6.28 & 6.34 & 6.41 & 6.48 & 6.55 & 6.64 & 6.75 & 6.88 & 7.05 & 7.33 \\
\hline & 0.0 & 0.1 & 0.2 & 0.3 & 0.4 & 0.4 & 0.6 & 0.7 & 0.8 & 0.9 \\
\hline 99 & 7.33 & 7.37 & 7.41 & 7.46 & 7.51 & 7.58 & 7.65 & 7.75 & 7.88 & 8.09 \\
\hline
\end{tabular}

Fonte: TNO (2005) 


\subsection{I Área Vulnerável a Radiação Térmica}

As áreas vulneráveis devido a ocorrência de incêndio em poça ou bola de fogo ficam delimitadas pelas linhas de isofluxo térmico correspondentes aos níveis de fluxo térmico de interesse. Estes níveis de interesses podem ser determinados usando-se a equação probit. A equação de probit para morte por queimadura, decorrente tanto de incêndio em poça como de bola de fogo, é dada por:

$$
Y=-14,9+2,56 \ln \left(\left.t \cdot\right|^{4 / 3} \cdot 10^{-4}\right)
$$

$\mathrm{t}=$ tempo de exposição à radiação térmica $[\mathrm{s}]$

$1=$ intensidade de radiação térmica $[\mathrm{W} / \mathrm{m} 2]$

\subsection{2 Área Vulnerável a Explosões}

Para a determinação da área vulnerável a explosão de nuvem não confinada, devido a liberação de substância inflamável, existem duas situações distintas que requerem tratamento diferenciado:

- liberações contínuas (ou transientes de duração longa o suficiente para que se estabeleça o estado estacionário na zona de interesse)

- liberações instantâneas ou quase instantâneas.

Para liberações contínuas de material inflamável, o centro da explosão é determinado pelo ponto ao longo do eixo da pluma onde a concentração da mistura gás inflamável/ar é estequiométrico. A massa de material inflamável que participa da explosão é usualmente assumida como sendo igual à massa contida na parte da nuvem com concentração entre o limite inferior e superior de inflamabilidade.

A explosão desta massa determina a que distâncias, a partir do centro da explosão, cada um dos níveis de sobrepressão especificados serão verificados. Cada nível de sobrepressão especificado corresponde ao valor que causa um determinado tipo de efeito sobre a população ou sobre os recursos vulneráveis. probit são:

Em caso de explosões, alguns dos efeitos que podem ser calculados através das equações de

- Para morte por hemorragia no pulmão:

$$
Y=-77,1+6,91 \ln \Delta P
$$

onde: $\quad \Delta \mathrm{P}=$ sobrepressão $\quad\left[\mathrm{N} / \mathrm{m}^{2}\right]$

- Para ruptura de tímpano:

$Y=-15,6+1,93 \ln \Delta P$

- Para danos estruturais:

$Y=-23,8+2,92 \ln \Delta P$

- Para quebra de vidros:

$$
Y=-18,1+2,79 \ln \Delta P
$$




\subsection{ANÁlise QuANTITATIVA dos RISCOS}

\subsection{Análise das Árvores de Eventos}

O cálculo de conseqüências deve ser precedido da "Análise da árvore de eventos - AEE" que permite definir as tipologias acidentais possíveis de ocorrência no sistema analisado. O "RED BOOK" da TNO (1997) define a árvore de eventos como "um modelo lógico que graficamente retrata a combinação dos eventos e circunstâncias na seqüência de um acidente". A AAE descreve a seqüência de fatos que pode se desenvolver a partir do cenário acidental em estudo, prevendo-se situações de sucesso ou falha de acordo com as interferências existentes, até a conclusão das mesmas com a definição das diferentes tipologias acidentais possíveis. As interferências consideradas contemplam ações, situações ou mesmo equipamentos existentes ou previstos no sistema em análise, as quais se relacionam com o evento inicial da árvore e que possam acarretar diferentes "caminhos" para o desenvolvimento da ocorrência, gerando, portanto diferentes tipos de fenômenos.

\subsection{2 Árvore de Eventos para o Sistema}

Quando ocorre um aumento da temperatura, de forma que haja condições para auto-detonação ou que seja feito algum acionamento acidental dos explosivos armazenados, e estando dentro da faixa de inflamabilidade, tem-se o efeito da ignição, ocorre o incêndio em uma bola de fogo ou explosão. Dependendo do grau de confinamento em que esteja, o incêndio será acompanhado pela geração de uma onda de sobrepressão, designada por "Explosão de Nuvem de Vapor". A intensidade deste evento está relacionada com o grau de confinamento, isto é, das barreiras existentes no local do vazamento. Assim, nos casos extremos, quando a nuvem está totalmente contida, tem-se a "explosão confinada" e quando não há qualquer tipo de contenção, a sobrepressão não se desenvolve. Nos casos reais sempre há algum grau de confinamento que deve ser levado em conta pelo modelo matemático da simulação através do parâmetro carga de explosivos.

Os mesmos eventos podem se desenvolver quando ocorre a liberação instantânea de uma grande massa de explosivo, como conseqüência de uma falha que provoque o colapso total do armazém. A ignição de uma grande massa de inflamável se dá como "bola de fogo".

A metodologia adotada nas simulações das conseqüências consistiu nas seguintes etapas:

- Consolidação das hipóteses acidentais;

- Seleção dos modelos matemáticos apropriados para as simulações;

- Levantamento de dados para os cálculos;

- Elaboração de cálculos preliminares;

- Simulação das hipóteses acidentais;

- Resumo e análise dos resultados.

Os cenários acidentais capazes de se desdobrarem em cenários de severidade crítica ou catastrófica foram submetidas à simulação de efeitos visando determinar a área de alcance e o respectivo nível de danos esperados. Para essa simulação foram considerados 3 cenários acidentais associadas à explosão catastrófica (100\% da carga máxima) e parciais ( $50 \%$ e $80 \%$ da carga máxima) do paiol. São elas:

- Hipótese 01 - Explosão catastrófica (100\% da Carga). Cenários acidentais: Taxa de calor liberado, Fireball, dispersão gaussiana. Vulnerabilidade: Taxas de radiação térmica e sobrepressão para Probit de 1\%, 50\%, 99\%.

- Hipótese 02 - Explosão catastrófica (80\% da Carga). Cenários acidentais: Taxa de calor liberado, Fireball, dispersão gaussiana. Vulnerabilidade: Taxas de radiação térmica e sobrepressão para Probit de 1\%, 50\%, 99\%.

- Hipótese 3 - Explosão catastrófica (50\% da Carga). Cenários acidentais: Taxa de calor liberado, Fireball, dispersão gaussiana. Vulnerabilidade: Taxas de radiação térmica e sobrepressão para Probit de 1\%, 50\%, 99\%.

- Verifica-se que as taxas de explosão para $100 \%$ da carga dos explosivos é referente a massa total de explosivos confinados no paiol que é de $4000 \mathrm{Kg}$.

- Para área vulnerável a radiação térmica foi considerada a equação de probit para morte por 
queimadura, decorrente tanto de incêndio em poça como de bola de fogo:

$$
Y=-14,9+2,56 \ln \left(t \cdot l^{4 / 3} \cdot 10^{-4}\right)
$$

- $\quad \mathrm{t}=$ tempo de exposição à radiação térmica $[\mathrm{s}]$

- $\quad 1=$ intensidade de radiação térmica [W/m2]

- Para área vulnerável a explosões foi considerada a equação de probit para morte por hemorragia pulmonar:

$$
Y=-77,1+6,91 \ln \Delta P
$$

$$
\Delta \mathrm{P}=\text { sobrepressão }\left[\mathrm{N} / \mathrm{m}^{2}\right]
$$

\section{RESULTADOS E DISCUSSÕES}

\section{I CálCulo da RadiaÇão}

Como citado anteriormente, considera-se a equação de probit para morte por queimadura, decorrente tanto de incêndio em poça como de bola de fogo, onde o tempo de exposição para cada percentual de fatalidade é citado abaixo:

Tempo de exposição à radiação térmica, para o caso explosão:

$\begin{array}{ll}\text { 1\% fatalidades: } & 30 \mathrm{~s} \\ \text { 50\% fatalidades: } & 20 \mathrm{~s} \\ 99 \% \text { fatalidades: } & 10 \mathrm{~s}\end{array}$

Cálculo do nível de radiação térmica correspondente (jato de fogo):

$$
\mathrm{Y}=-14,9+2,56 * \ln \left(\frac{\mathrm{t} * \mathrm{I}^{4 / 3}}{10^{4}}\right) \quad \Rightarrow \quad \mathrm{I}=\left[\frac{10^{4} * \exp [(\mathrm{Y}+14,9) / 2,56]}{\mathrm{t}}\right]^{3 / 4}
$$

A seguir, observa-se o cálculo da radiação térmica versus \% de fatalidade para cada hipótese.

\begin{tabular}{|l|c|c|c|c|}
\cline { 2 - 5 } \multicolumn{1}{c|}{} & Mortalidade $\%$ & Valor Probit & Tempo (s) & Radiação Térmica [W/m2] \\
\hline CASO 1 & $1 \%$ & 2,67 & 30 & 13417,5 \\
\hline CASO 2 & $50 \%$ & 5 & 20 & 35991,4 \\
\hline CASO 3 & $99 \%$ & 8,09 & 10 & 149667 \\
\hline
\end{tabular}

Fonte: Autores.

Com a equação abaixo, calcula-se a distância entre o epicentro da explosão ao alvo para cada hipótese, ou seja, o raio mínimo de segurança.

$$
\mathrm{I}=828000 \mathrm{~m}^{\wedge} 0,771 / 1^{\wedge} 2
$$

$\ln (\mathrm{I})=\left(\mathrm{m}^{0,771} / \mathrm{r}^{2}\right) \times \ln (828000)$

$1=$ Radiação Térmica $\left[\mathrm{W} / \mathrm{m}^{2}\right]$

$\mathrm{m}=$ massa total de substancia explosiva $[\mathrm{Kg}]$

$\mathrm{r}=$ distância do epicentro da explosão ao alvo [m]

Para cada cenário acidental estudado, as distâncias apresentadas foram consideradas a partir 
do ponto onde ocorreu a liberação da substância. Para determinamos a distância tomamos com base a Hipótese 1, visto que é na mesma que ocorre a explosão catastrófica com $100 \%$ da carga.

Hipótese $1-100 \%$ da carga $(4000 \mathrm{Kg})$

\begin{tabular}{|l|c|c|}
\cline { 2 - 3 } \multicolumn{1}{c|}{} & Mortalidade \% & Distância $(\mathrm{m})$ \\
\hline CASO 1 & $1 \%$ & 29,3 \\
\hline CASO 2 & $50 \%$ & 27,89 \\
\hline CASO 3 & $99 \%$ & 26,16 \\
\hline
\end{tabular}

Fonte: Autores.

\subsection{CálCulo da Sobrepressão} pulmonar:

Para área vulnerável a explosões foi considerada a equação de probit para morte por hemorragia

$$
Y=-77,1+6,91 \ln \Delta P
$$

$$
\Delta \mathrm{P}=\text { sobrepressão }\left[\mathrm{N} / \mathrm{m}^{2}\right]
$$

Como no cálculo da distância, também foi considerado a Hipótese 1, pois onde se encontra $100 \%$ da carga.

\begin{tabular}{|l|c|c|}
\cline { 2 - 3 } \multicolumn{1}{c|}{} & Mortalidade $\%$ & Sobrepressão(bar) \\
\hline CASO 1 & $1 \%$ & 1,0317 \\
\hline CASO 2 & $50 \%$ & 1,445 \\
\hline CASO 3 & $99 \%$ & 2,2605 \\
\hline
\end{tabular}

Fonte: Autores.

\subsection{EFEITOS DA RADIAÇÃo TÉRMICA}

A radiação térmica procedente de um incêndio pode causar efeitos adversos tanto nas pessoas como nas instalações. De uma maneira direta, os indivíduos expostos podem sofrer queimaduras de diversos graus, podendo levar até a morte dependendo da intensidade da radiação térmica recebida e do tempo de exposição. Por outro lado, os efeitos térmicos podem afetar edifícios e instalações, fragilizando estruturas e destruindo-os parcial ou totalmente, o que pode dar origem à morte ou ferimentos em indivíduos não expostos diretamente à radiação térmica.

A radiação térmica que pode causar danos às pessoas e aos materiais conforme o nível e o

\begin{tabular}{|c|c|}
\hline Radiação térmica $\left(\mathrm{kW} / \mathrm{m}^{2}\right)$ & Características \\
\hline 1 a 1,6 & Radiação suportável sem o uso de roupas protetoras \\
\hline 4 a 5 & Radiação suportável com o uso de roupas protetoras \\
\hline 12 & Limite para ignição de vegetação \\
\hline 12,5 & $\begin{array}{l}\text { Radiação que provoca queimaduras letais. Energia } \\
\text { mínima para ignição de madeira. }\end{array}$ \\
\hline 25,0 & $\begin{array}{l}\text { Energia mínima para a ignição espontânea da } \\
\text { madeira. }\end{array}$ \\
\hline 37,5 & $\begin{array}{l}\text { Radiação que provoca queimaduras letais. Perigo a } \\
\text { vida. Danos a equipamentos. }\end{array}$ \\
\hline
\end{tabular}
tempo de exposição, segue abaixo um resumo:

Fonte: Purple Book (p. 5.1, 2005) 


\subsection{EFEITOS DA SOBREPRESSÃO}

A literatura cita que as ondas de sobrepressão provenientes de explosões possuem potencial para provocar danos às edificações podendo levar a cenários mais sérios, tal como a escalada de eventos (efeito dominó).

Muitas das informações disponíveis na literatura sobre os efeitos dos danos causados pelas explosões são derivadas de experiências com armas nucleares e de avaliações teóricas. Clansey (1972) cita alguns níveis de danos segundo o pico de sobrepressão de uma explosão conforme apresentado na tabela abaixo

\begin{tabular}{|c|c|}
\hline Efeitos & Sobrepressão (Bar) \\
\hline Quebra de vidros & 0,01 \\
\hline Danos a estruturas menores & 0,03 \\
\hline Destruição quase completa de casas & 0,34 a 0,48 \\
\hline $\begin{array}{c}\text { Provável destruição completa de } \\
\text { estruturas civis e equipamentos } \\
\text { pesados (5,4 ton) }\end{array}$ & 0,69 \\
\hline $\begin{array}{c}\text { Destruição de 99\% do tanque metálico } \\
\text { para combustíveis }\end{array}$ & 1,38 \\
\hline
\end{tabular}

Fonte: Clansey (1972)

Com os resultados acima citados e analisando as tabelas de efeitos da radiação e sobrepressão, conclui-se que a ocorrência da explosão catastrófica com 100\% das cargas traz danos irreparáveis como podemos observar abaixo:

Se algum trabalhador estiver presente a um raio mínimo de $26,17 \mathrm{~m}$, a probabilidade de óbito é de $99 \%$, além disso, podemos concluir que os valores da radiação e da sobrepressão nessa condição são suficientes para provocar queimaduras letais, perigo a vida e danos a equipamentos. Contudo se o mesmo estiver a uma distância de 27,89 m do epicentro da explosão, a probabilidade de morte diminui para $50 \%$, porém os efeitos decorrentes da radiação e sobrepressão são os mesmo do caso citado anteriormente. Porém, caso o funcionário esteja a 29,3 m de distância da explosão, a probabilidade reduz drasticamente para apenas $1 \%$, mas os efeitos da radiação e sobrepressão podem provocar queimaduras letais e destruição de estruturas civis, respectivamente.

\section{CONCLUSÕES}

O armazenamento de explosivos é uma tarefa que requer muitos cuidados, visto que geralmente acidentes envolvendo paióis causam danos enormes, irreversíveis e fatais. Este trabalho permite-se a avaliação dos impactos que um acidente envolvendo cargas explosivas armazenadas pode causar ao local e a comunidade.

Fazermos uma análise quantitativa de risco na execução do projeto é de suma importância, visto que por meio de métodos matemáticos podemos dimensionar e mostrar as áreas mais propicia a danos caso algum sinistro ocorra. A análise apresentada nesse estudo foi eficaz, pois além de podermos delimitar o raio de segurança, observamos os possíveis efeitos que a radiação e sobrepressão podem causar a vida do homem.

Por fim, observou-se a importância do estudo para conscientização e cuidados relevantes no armazenamento dos explosivos, visando em primeiro lugar a saúde e segurança dos trabalhadores. 


\section{REFERÊNCIAS}

ANP. Disponivel em: www.anp.gov.br. Acesso em: 15/11/2013.

CETESB. Manual de orientação para elaboração de estudos de análise de riscos. 2000.

THOMAS, J.E, organizador.Fundamentos de Engenharia de Petróleo. ed. Interciência, Rio de Janeiro, 2001.

GUIA TRABALHISTA. Norma Regulamentadora No 19 - Explosivos. Disponível em: < http://www.guiatrabalhista.com.br/legislacao/nr/nr19.htm>. Acesso em: 20 Nov. 2013.

DINIZ, F; OLIVEIRA,L,F; BARDY,M; VISCO,N. Apostila do Curso Sobre Estudo de Análise de Riscos e Programas de Gerenciamento de Riscos.

Disponível em: < http://www.mma.gov.br/estruturas/sqa pnla/ arquivos/ 7.pdf> $>$. Acesso em: 18 NOV.2013.

LETTA, M.C.K; SZAJNBOX,M; SANTOS, J. R. Análise de Riscos na Manobra e Armazenamento de Torpedos Pesados Sobre as Áreas Habitadas e Rodovias Próximas. Disponível em: <http://www.ipen.org.br/ downloads/XXII/trabajos/92\%20\%20\%20Marcia\%20Letta\%20COMPLETO $\% 20$ (Brasil).pdf $>$. Acesso em: 21 NOV. 2013.

MENDES, R. Programa de Avaliação e Gerenciamento de Riscos.

SEWEL, R.G.S., ZULKOSKI, T.R. e KINNEY, G.F. - "Blast Parameter Characterization", Naval Weapons Center Technical Report TP 5920, Part 1, Volume 2, China Lake, California, 1979.

STULL, D.R. - "Fundamentals of Fire and Explosion", AIChE Monograph Series 73 nE 10, p.72, 1977.

THE ROYAL SOCIETY OF LONDON. Risk assessment. London; 1983 [Report of Royal Society Study Group].

TNO. Purple Book CR reference manual. 2006. 